\title{
A "Weak" Reflection on Unpredictability and Social Theory
}

\section{Charalambos Tsekeris ${ }^{1}$ and Konstantinos Koskinas ${ }^{2}$}

\author{
${ }^{1}$ Department of Psychology, Panteion University of Social and Political Sciences, 136 Syngrou Ave., 176 71, \\ Athens, Greece. E-mail: tsekeris@gmail.com \\ ${ }^{2}$ Department of Psychology, Panteion University of Social and Political Sciences, 136 Syngrou Ave., 176 71, \\ Athens, Greece. E-mail: kkoski@panteion.gr
}

\begin{abstract}
This concise reflection seeks to comprehensively interconnect the well-established theoretical and methodological logic of self-organization with a new reflexive ethos and aesthetic of epistemic modesty and humility. A brief elaboration on the issue of unpredictability further encourages a suitable and sustainable analytic framework for generating, developing and cultivating a radical ethics/aesthetics of epistemological weakness, as well as a sense of less strong and more reflexive sociological/philosophical worldview.
\end{abstract}

Keywords: Knowledge, Self-Organization, Epistemology, Reflexivity, Social Theory

Acknowledgement: This reflection presents personal views of the authors. Particular thanks are expressed to the staff of the Center for the Psycho-Sociological Research on the Governance of Virtual Communities (OMEGA Research Center), Department of Psychology, Panteion University, Athens, Greece.

\section{Introduction}

Since the sixties, an overwhelming paradigm shift in the disciplines of science (system thinking and evolutionary thinking), philosophy and "weltanschauung" has been gradually underway. Self-organization came up to strictly exclude any strong "transcendental" or "metaphysical" theoretical need "to assume a first mover of the world that is not moved itself and to think of the emergence of the world in terms of a creatio-ex-nihilo. The substance of matter is that it is in permanent movement and permanently produces itself, i.e. it organises itself on various organisational levels" (Fuchs 2003a: 7).

This brief reflection seeks to show a simple thing: self-organization entails that it is not enough for social theory to be "refutable" or "provisional" (Cilliers 2005a); it should be definitely weak and imperfect because of the unpredictable co-emergence of knower and setting or knowledge and action/experience (see e.g. Maturana \& Varela 1987) ${ }^{1}$, as well as because of the very epistemological circularity of the theoretical accounts on this coemergence ${ }^{2}$.

As enactivist scholars B. Davis and D.J. Sumara (1997: 110) have argued, knowing "exists in the interstices of a complex ecology or organismic relationality". In an "enactivist" or "performativist" conception of social order, social structures, relations, patterns, connections and identities are real/imaginary quantities that exist only partially, because they are continuously "at stake" in attempts to render them a little bigger or a little smaller. We are all in the permanent business of re-negotiating, re-constructing and acting performatively upon them. Therefore, we all contribute to the "reality status" of what is described and explained (see Pels 2002).

2 In other words, a general theory of selforganization seems to be a suitable and sustainable analytic framework not only for articulating "a general concept of co-operation" (Fuchs 2003a: 2), but also for generating, developing and cultivating a radical ethics/aesthetics of epistemological weakness, as well as a sense of less strong and more reflexive sociological/epistemological worldview. These elements could possibly be "the typical contributions of (social) science to the shape of the world. It could say things that are interestingly feeble, shaky, 
Social theory must thus cultivate a selfreflexive ethos of imperfection, against all the purism and asceticism of truth-seeking, which still rages academic research. The continuous attempt to understand (or to model) human complex systems necessarily involves epistemic modesty, as well as an ethical sense of epistemological weakness that especially focuses on our "natural" incapacity to predict. Following the Nietzschean Eternal Return, the reflexive conception of self-organization requires from us to openly accept (and energize) the responsibility for our claims or models, although we know they are flawed. So, self-organization also involves generosity, justice, honesty, integrity, sincerity and sharing.

These further call us to comprehensively elaborate on the deeper reflexive ethical implications and consequences of selforganization in the particular analytic contexts of unpredictability and social theory.

\section{The Issue of Unpredictability}

Modernity, as a social and historical category, has been closely associated to the "received" or "conventional" strong ambition to know, predict and manipulate (engineer) the world in toto with total certainty. Human life, however, is inherently dynamic: it is inescapably and ceaselessly changing and polymorphous (kaleidoscopic). In other words, it may be simple or chaotic, easy or hard, boring or exciting, happy or miserable, beautiful or evil. To put it very simply, life is never the same. Change is actually constitutive of all sorts of human co-existence/co-operation and social living over the ages.

Human behavior is mostly ambiguous and non-linear; it is characterized by a varied disproportionality between (changes to) the input and the outcome (the so-called butterfly ef$f e c t)$. In other words, a small cause often has large effects (see e.g. Urry 2005: 6, Hayles 1991: 11). In addition, "similar causes can have different effects and different causes similar effects; small changes of causes can

risky, and weird. Political and entrepreneurial metaphors, work-styles, output indicators and leadership models wreak havoc when they are too diligently pursued in science" (Pels 2003: 219). have large effects whereas large changes can also only result in small effects. Hence conceptualizing globalization as an aspect of selforganizing systems enables us to assume that in a globalizing world there are complex, nonlinear causal relationships that are stretching across large spatio-temporal distances" (Fuchs 2003b: 112).

That is why global (or glocal) social networks are chaotic systems: determinism is structurally coupled with the role of agency, surprise, contingency and unintended/unforeseen consequences and sideeffects (unpredictability). Self-organized patterns of interconnections, interrelations and interdependencies are continually created and re-created through an "endless dance of coemergence" (Waldrop 1992: 75). And that is why any social theoretical attempt to change (or to save) the world is indeed too weak: "social development can't be steered because society is a complex, self-organizing system" (Fuchs 2003b: 164). Nobody can actually (voluntaristically or not) situate her/himself above societal dynamics, independent of her/his authority, prestige, institutional position or epistemological standpoint. In any case, this should not subtract from the huge importance and significance of (knowledgeable) human agency and intervention. Especially in periods of crisis and acute struggle, human agency and intervention can still make a decisive historical difference for all of us and for the next generations.

Furthermore, the multiscale nature and complexity of self-organized social networks are crucial features in better understanding (and modeling) them. Both methodological and epistemological advances in human complex systems (see Tsekeris 2009) are providing an integrated framework, without however achieving true (strong) predictive power of their behavior. Of course, regularities are not excluded: "laws can be proposed and validated (or negated) via empirical means, but they can be formulated only in a probabilistic manner" (Katerelos 2007). This particularly denotes that "unpredictability" and "indeterminacy", as significant constitutive features of 
the social world, should always be placed at the centre of the analysis ${ }^{3}$.

After all, what about the very future of human complex systems? A very simple, modest and pragmatic answer is that we just "cannot predict or control this future, these futures. One lesson of Chaos Theory is that no-one else can, either. The will to predict is always doomed and counter-productive. Life, whether social, cultural or digital, is inherently complex" (Hodge \& Lally 2006) ${ }^{4}$. This is indeed an epistemologically weak answer!

In the highly contingent, speedy, dynamic and risky universe of self-organized social networks, any strong, authoritarian "top-down" control (or promethean engineering) of information spread, opinion formation, free will and self-expression is completely impossible and undesirable. Equally undesirable is a predictable, linear, hierarchical, stable, orderly, homogenous and pure human world (unpredictability is not a curse anymore).

This would probably be a very hopeless, colorless, dull and boring world: A completely grey social universe (against human nature itself!). In addition, there is indeed a small degree of optimism about the future, by strategically focusing upon critical possibilities rather than limitations. As Christian Fuchs perceptively argues "we should act in order to realise an alternative, democratic, participatory, humane form of globalization that is based on

Within current complexity research, "unpredictability" is frequently used in two different senses (Katerelos 2007): (1) On the one hand, it "involves the overwhelming failure of the modern sociological (and social scientific) projects to fully contain social dynamics, or to obtain full analytic access to future social and historical developments". (2) On the other hand, it "denotes an essential feature concerning the nature and character of all complex or chaotic systems ... In a "self-organizing" or "autopoietic" social universe, where (dis)order, (mis)understanding and (dis)unity reflexively come from agonistic competition, irreducible diversity, mutual evolution, emergence, or chaotic noise..., the future just becomes a mere possibility".

$4 \quad$ A quite simple mathematical analysis could easily show that, even in simple and explainable systems, which obey Newton's laws of motion, we cannot always and accurately predict what is going to happen next. This is because of a persistent instability, as well as of an undecidable multiplicity of forces that variously affect and act upon an object. For sure, any attempt to predict a simple system's future behavior over long times will be defeated. Of course, this does not mean that we can say nothing about the dynamic properties and processes of the system. global alliance technology, global ecological sustainability, global wealth, a global participatory agora, and a global noosphere. New forms of globalization and governance are needed, globalization is in need of global wisdom and global co-operation" (Fuchs 2003b: 164).

The future dynamic evolution of emerging social networks (online and offline) can be coarsely projected up to a certain time horizon (predictability horizon), but it cannot be fully predicted with certainty and precision in the long run (see Katerelos \& Koulouris 2004). Namely, predicting the future of human complex systems could be rather considered as an epistemologically weak, irresolvable riddle. But the irreducible social, cultural and historical potential of dynamic social networking, recreation, co-action, co-operation and selforganization is nevertheless here, for better or for worse!

\section{Inventing a Weak Social Theory}

Recent theoretical and methodological advances within social complexity research in general help us to seriously and imaginatively re-think and re-decide about the ambiguous, complicated, persistent, and highly disputed issue of predictability/unpredictability. It is likely that many of the arrogant (self-assured) long-term predictions unreflexively and uncritically overestimate the role and limits of science and technology ${ }^{5}$. But the general conclusion that "we cannot make purely objective and final claims about our complex world", clearly entails that "we have to make choices and thus we cannot escape the normative or ethical domain" (Cilliers 2005a: 259).

5 These developments tend to gradually and irreversibly "bend, shift, and transform the limits of what we think is possible. It is virtually impossible to predict the full consequences of all of our actions, and we cannot predict how society and the global order might change in response to new technologies ... but science should not ignore our moral or ethical responsibility to consider all the risks either" (Virdi 2008: 41). According to Jean-Pierre Dupuy's perceptive observations, technoscience "cannot isolate itself from social responsibility or should be given a monopoly on decision-maker power" (Virdi 2008: 41). In doing so, ICTs-and-Society can indeed serve the global aim of supporting "the evolution of academic knowledge exchange to an electronic democracy" (Whitworth \& Friedman 2009). 
According to our opinion, this ethical domain is better expressed by the innovative and provocative conception of weak social theory, as originally conceived by the Dutch sociologist Dick Pels (2003). This is directly opposed to both the systematic reinforcement of the hegemonic "grand conception of sociology's role" (see Hammersley 1999) and the methodical/strategic concealment of the essential "epistemological circularity" of sociological/philosophical accounts, which eventually isolate us from the ethics of "imperfection" and epistemic modesty. Sociological/philosophical and social theoretical knowledge is inescapably a very fragile, unstable, incomplete, asymmetrical and contingent thing.

In this analytic respect, weak social theory importantly advances "intellectual humility and tolerance" (Rosenau 1992: 22), recalling many essential postmodernist/poststructuralist features: No more compelling and compulsory truths, great and indubitable certainties (dogmas), or all-purpose grand methodologies. And no more need to forcibly extract any universally binding agreement. Social theory must now self-consciously recognize and celebrate itself as inherently open, refutable, soft, weak and vulnerable, "refusing to flex the muscle of a male-dominated epistemology" (Pels 2003: 217).

For weak social theory, to say that a sociological or philosophical argument carries overwhelming force, or that it stands up in a definitely unproblematic way, is exactly to "find it distasteful or even slightly obscene. To say: 'that is a very vulnerable argument', is to pay a compliment to it" (Pels 2003: 220). In this sense, we must be proud of our (constitutive) weakness and reflexively embrace our own anti-universalistic politics of knowledge, primarily pointing our epistemic guns at ourselves, rather than at everyone else in order to dogmatically achieve maximum (linear) diffusion and global consensus. In the first place, therefore, social/ethical theorizing must be seen as a way of persuading ourselves!

Hence, most importantly, our knowledge's own (unavoidable) circularity and selforganization is openly acknowledged and actively celebrated. Weak social theory explicitly champions a non-hasty and modest "circular reasoning" over arrogant and self-sufficient (self-immunizing) rationalist/foundationalist claims for intellectual access to totality. In other words, it explicitly champions the radical (early) ethnomethodological conception of (constitutive) reflexivity that comprehensively entails "the intimate interdependence between representation and represented object... such that the sense of the former is elaborated by drawing on knowledge of the latter, and knowledge of the latter is elaborated by that which is known about the former" (Woolgar 1988: 33).

Such a kind of performative "knowledge politics" is neither self-refuting nor a relativism of the all-cats-are-grey variety (weak knowledge is not "any" knowledge), since it nonopportunistically offers itself as a weak and self-organizing criterion of truth, by critically displaying the dialectical "projective relationship between the spokesperson and that which is spoken for" (Pels 2000: 17). This ultimately waives all authoritarian macho claims for "independent" realities, "transcendental" truths and "obligatory" epistemological foundations (Pels 1995: 1036), paving however the enthusiastic and promising way to an ethically responsible and radically reflexive mode of critique ${ }^{6}$.

As the radical skeptical ethics of selforganization and circular reflexive reasoning is being brought right at the heart of current epistemological/sociological and interdisciplinary debates, we do maximize our fruitful chances to surprisingly discover a wholly new intellectual and academic life conduct: "Less egotism, both individual and collective, and more awareness of how we all constitute each other: this could be a path toward lowering intellectual acrimony in the future" (Collins 2002: 70). In such terms, caring for the other signifies an essential normative prerequisite for both social and scientific living (Tsivacou 2005: 520-522), against old modern hardness and classical power talk.

This also champions a creative on-going interplay between the ontological, the epistemological and the ethical, according to Karl Mannheim's famous "magic triangle" (Pels 2003). 


\section{Final Remarks}

In this specific analytic context, we energetically promote a genuine, phronetic ${ }^{7}$ and anti-hegemonic stance of epistemological weakness, dynamically connecting reflexivity and reflexive self-organization, as a rather community level concern, with the ethics of sociological/philosophical and organizational research and theory. The social researcher now learns to peacefully keep in mind "both how little the single scientist knows in relation to the total community of inquirers, and a respect for the complexity of reality" (Kalleberg 2007: 141). We thus accomplish a provocative dialogical expansion of the very project of reflexive sociology/epistemology, which is indeed integral to good (serious) cultural production (see Tsekeris and Katrivesis 2008).

Of course, this alternative, non-ascetic approach, which self-confidently stands against all transcendental purist aspirations to (Platonic) perfectionism, creatively encourages "bounded" or "limited" knowledge (Cilliers 2005a, 2005b). For Paul Cilliers, however, self-reflexive modest claims "are not relativistic and, therefore, weak ... We can make strong claims, but since these claims are limited, we have to be modest about them" (Cilliers 2005a: 260, 263). That is, a modest position should definitely be a responsible position, but not a weak one. But complexity, self-organization and modesty, in our opinion, goes hand in hand with epistemological weakness (not epistemological vagueness or insipidity), a sense of "turning the other cheek", or a sense that we do not necessarily have to be compulsory/obligatory and strong to stand up to the strong, and thus come to resemble our epistemological opponents or enemies (in a mimetic way). What we vitally need here is perhaps to "include conscious consideration of a range of formal ethical positions and adoption of a particular ethical stance" (Guillemin and Gillam 2004: 275), over against the multiple and underlying "dangers of complacency" (Rachel 1996).

Of course, the rather weak Aristotelian conception of "phronesis" (practical, limited wisdom), as a sign of epistemic humility and honesty, is quite relevant here (see Flyvbjerg 2001).
Yet, it is almost certain that not everyone is willing to easily withdraw or refrain from the positive "enlightenment" ambition of social theory to heroically champion "strong" privileged knowledge over fragile, local, contested and scientifically ungrounded lay beliefs, as well as to actively engage in large-scale political and legislative enterprises, establishing grand rational (and fully linear and predictable) structures within society. 


\section{References}

Cilliers, P. (2005a) Complexity, Deconstruction and Relativism. Theory, Culture \& Society 22(5): 255-267.

Cilliers, P. (2005b) Knowledge, limits and boundaries. Futures 37: 605-613.

Collins, R. (2002) On the acrimoniousness of intellectual disputes. Common Knowledge 8(1): 47-70.

Davis, B. and Sumara, D.J. (1997) Cognition, complexity and teacher education. Harvard Educational Review 67(1): 105125.

Flyvbjerg, B. (2001) Making Social Science Matter. Why Social Inquiry Fails and How It Can Succeed Again. Cambridge: Cambridge University Press.

Fuchs, C. (2003a) Co-Operation and Self-Organization. tripleC - Cognition, Communication, Co-operation: Open Access Journal for a Global Sustainable Information Society 1(1): 1-52.

Fuchs, C. (2003b) Globalization and Self-Organization in the Knowledge-Based Society. tripleC - Cognition, Communication, Co-operation: Open Access Journal for a Global Sustainable Information Society 1(2): 105-169.

Guillemin, M. and Gillam, L. (2004) Ethics, Reflexivity, and "Ethically Important Moments" in Research. Qualitative Inquiry 10(2): 261-280.

Hammersley, M. (1999) Sociology, What's It For? Sociological Research Online 4(3).

Hayles, N. K. (1991) Chaos Bound: Orderly Disorder in Contemporary Literature and Science. Ithaca, NY: Cornell University Press.

Hodge, B. and Lally, E. (2006) Cultural planning and Chaos Theory in Cyberspace: some notes on a Digital Cultural Atlas Project for Western Sydney. Fibreculture Journal [online], Issue 9.

Kalleberg, R. (2007) A Reconstruction of the Ethos of Science. Journal of Classical Sociology 7(2): 137-360.

Katerelos, I. (2007) “Unpredictability”. In G. Ritzer (ed.) Blackwell Encyclopedia of Sociology. London: Blackwell Publishing (Blackwell Reference Online).

Katerelos, I. and Koulouris, A. (2004) Is prediction possible? Chaotic behavior of Multiple Equilibria Regulation Model in cellular automata topology. Complexity 10(1): 23-36.

Maturana, H. and Varela F. (1987) The tree of knowledge: The biological roots of human understanding. Boston: Shambhala Press.

Pels, D. (1995) The Politics of Critical Description: Recovering the Normative Complexity of Foucault's pouvoir/savoir. American Behavioral Scientist 38(7): 1018-1041.

Pels, D. (2000) Reflexivity: One Step Up. Theory, Culture \& Society 17(3): 1-25.

Pels, D. (2002) Everyday Essentialism. Social Inertia and the Münchhausen Effect. Theory, Culture \& Society 19(5/6): 6989.

Pels, D. (2003) Unhastening Science: Autonomy and Reflexivity in the Social Theory of Knowledge. Liverpool: Liverpool University Press.

Rachel, J. (1996) Letter from London. EASST Review 15(4).

Rosenau, P. M. (1992) Post-modernism and the Social Sciences. Insights, Inroads, and Intrusions. Princeton, NJ: Princeton University Press.

Tsekeris, C. (2009) Advances in Understanding Human Complex Systems. Australian Journal of Basic and Applied Sciences 3(4): 4040-4045.

Tsekeris, C. and N. Katrivesis (2008) Ethical Reflexivity and Epistemological Weakness. Tamara Journal for Critical Organization Inquiry 7(3): 26-34.

Tsivacou, I. (2005) The Ideal of Autonomy from the Viewpoint of Functional Differentiation / Integration of Society. Systems Research and Behavioral Science 22: 509-524.

Urry, J. (2005) The Complexity Turn. Theory, Culture and Society 22(5): 1-14.

Virdi, J. (2008) Bridging the Knowledge Gap: Examining Potential Limits in Nanomedicine. Spontaneous Generations: A Journal for the History and Philosophy of Science 2(1): 25-44.

Waldrop, M. M. (1992) Complexity. New York: Simon \& Schuster.

Whitworth, B. \& Friedman, R. (2009) Reinventing academic publishing online. Part II: A socio-technical vision. First Monday, 14(9) In: http://firstmonday.org/htbin/cgiwrap/bin/ojs/index.php/fm/article/viewArticle/2642/2287.

Woolgar, S. (1988) Science: The Very Idea. London: Tavistock.

\section{About the Author}

Charalambos Tsekeris

Charalambos Tsekeris graduated with Distinction from Brunel University (West London, UK) and earned his doctoral degree in Reflexivity from Athens Panteion University (Department of Sociology). He is currently lecturing at Athens Panteion University (Department of Psychology) and holding the post of Ass. Professor of Sociology at Hellenic Police Academy. He 
is also a Member of the Hellenic Sociological Association and the Hellenic Sociological Society (HSS), co-editor of the peerreviewed Intellectum Journal, and a researcher at the Center for the Psycho-Sociological Research on the Governance of Virtual Communities (OMEGA Research Center). He has more than 50 publications in peer-reviewed journals and edited volumes. E-mail: tsekeris@gmail.com

\section{Konstantinos Koskinas}

Konstantinos Koskinas is Associate Professor of Sociology and Director of the Center for the Psycho-Sociological Research on the Governance of Virtual Communities (OMEGA Research Center), Department of Psychology, Panteion University, Athens, Greece. He is also a Member and former President of the Hellenic Sociological Association and author of many publications on culture, knowledge, power, politics, virtual communities, and transdisciplinary research in general. E-mail: kkoski@panteion.gr 